\title{
0 litígio estratégico na luta antitransgênicos no Brasil
}

Strategic litigation against the transgenics in Brazil

\author{
Cristiana Losekann \\ Luiza Duarte Bissoli
}

\section{RESUMO}

0 artigo examina o uso de estratégias judiciais nas lutas contra os transgênicos no Brasil. 0 objetivo é entender os mecanismos que levam essas organizações a buscarem no judiciário uma forma de influenciar em decisões políticas. Argumentamos que a constituição deste tipo de estratégia deve entendida a partir da observação das razões que levam organizações a recorrerem à ação judicial. Nesse sentido analisamos que em certos aspectos o apelo ao judiciário revela uma limitação das possibilidades de entendimento via espaços de participação e deliberação. Além disso, evidenciamos que o litígio estratégico, nesse conflito, ocorre de formas distintas: por um lado, refere-se ao conteúdo da questão proposta judicialmente e, por outro, à preservação do espaço de participação e atuação das organizações.

Palavras-chave: Litígio estratégico. Movimentos sociais. Transgênicos. Democracia.

\begin{abstract}
The article examines the use of legal strategies in the struggle against GMOs in Brazil. The goal is to understand the mechanisms that lead these organizations to seek justice in a way to influence policy decisions. We argue that the constitution of this type of strategy is understood from the observation of the reasons why organizations to resort to legal action. In this sense we analyze that in certain respects the appeal to the judiciary reveals a limitation of the possibilities of understanding via spaces for participation and deliberation. In addition, it noted that the strategic litigation, this conflict occurs in different ways: on the one hand, refers to the content of the question posed in court and, second, the preservation of space for participation and performance of organizations.
\end{abstract}

Keywords: Strategic litigation. Social movements. Transgenics. Democracy. 


\section{Introdução}

A presente proposta examina a ação judicial como ação estratégica de organizações da sociedade civil brasileira na tentativa de criar barreiras para a execução de políticas que impactam o meio ambiente. Nesse sentido, partimos do estudo do processo de liberação dos transgênicos no Brasil para entender os mecanismos que levam essas organizações a buscarem no judiciário uma forma de influenciar em decisões políticas.

Ao tratar sobre a judicialização temos em conta que várias são as possibilidades de definição do conceito. Para Vallinder (1995, apud CARVALHO, 2004), há tipos dois tipos de judicialização: frow without, que representa uma reação do Judiciário provocado por terceiro com fins a revisar a decisão de poder político tomando como base a Constituição; e frow within, que é quando a administração pública usa o aparato judicial. No Brasil, Koerner e Maciel (2002) ${ }^{1}$ fizeram um balanço dos sentidos que o termo ganhou no país. Segundo eles, a “[...] ideia de judicialização envolve tanto a dimensão procedimental quanto substantiva do exercício das funções judiciais" (p.114). Além disso, eles apontam que os sentidos e os usos foram multiplicados porque a expressão entrou no debate público, apesar de ser mais utilizada no sentido normativo.

Sugerimos que o tema da judicialização dos conflitos ambientais é mais bem entendido se analisadas as razões que levam organizações a recorrerem à ação judicial. Nesse sentido, analisamos que em certos aspectos o apelo ao judiciário revela uma limitação das possibilidades de entendimento via espaços de participação e deliberação. Além disso, evidenciamos que a judicialização desses conflitos pode ocorrer de formas distintas: por um lado, refere-se ao conteúdo da questão proposta judicialmente e, por outro, à preservação do espaço de participação e atuação das organizações.

Duas pesquisas sustentam esse trabalho. A primeira teve como objeto a atuação mais ampla das grandes organizações ambientalistas no primeiro mandato do governo Lula. A metodologia utilizada foi qualitativa com a realização de entrevistas com representantes dessas organizações e do governo, e análise de documentos de algumas ações civis públicas. As organizações ligadas às lutas antitransgêncios que foram escutadas nesta 
pesquisa foram: AS-PTA (Agricultura familiar e ecologia); Greenpeace; IDEC (Instituto de defesa do consumidor). Além disso, foram ouvidos os representantes do Ministério do Meio Ambiente, e da CTNBio (Comissão Técnica Nacional de Biossegurança).

A outra pesquisa foi realizada entre 2012 e 2013 a partir do exame de processos do tipo Ação Civil Pública (ACP) e Ação Direta de Insconstitucionalidade (Adin), predominantemente das ações constantes no Superior Tribunal de Justiça (STJ), no STF e no Tribunal Regional Federal da 1a Região (TRF1), a partir de 1998 até 2012, consultadas através do site oficial dos referidos órgãos de Justiça. Inseriu-se, separadamente, no campo de busca da jurisprudência os termos transgênico e OGM. Após a análise das ações, produziram-se dados quantitativos e qualitativos neste tema, bem como, a partir de uma perspectiva genealógica, buscou-se identificar seus atores e o processo político anterior que culminou na judicialização ambiental.

\section{Da regulamentação da lei de biossegurança à luta antitransgênicos}

Os conflitos em torno da liberação dos transgênicos envolvem diferentes discursos entre eles destacamos: ambiental (que por sua vez também é heterogêneo), científico, econômico (também podemos entender por dois lados o discurso econômico: privatista e empresarial e, desenvolvimentista do governo) e do consumo. Estes discursos estão articulados na perspectiva de diferentes atores. Entre os setores favoráveis à liberação estão o setor empresarial do agronegócio, o setor tecnológico e científico de pesquisa e produção de OGMs (Organismos Geneticamente Modificados $)^{2}$, o Ministério da Agricultura e o Ministério da Ciência e Tecnologia, além de setores políticos específicos que advogam o desenvolvimento dos transgênicos como uma forma de acabar com a fome e sugerem que a posição contrária significa um "entravismo" de interesse estrangeiro no desenvolvimento do Brasil. Personalidade emblemática desta ideia é o político Aldo Rabelo, do PCdoB. Entre os setores contrários à liberação estão o Ministério do Meio Ambiente, o Ministério do Desenvolvimento Agrário, organizações ambientalistas (destacando-se o Greenpeace), 
organizações de defesa dos direitos dos consumidores (IDEC - Instituto de Defesa dos Consumidores), movimentos sociais (destacando-se a ASPTA - Assessoria e Serviços a Projetos em Agricultura Alternativa e a Terra de Direitos), cooperativas de produtores (destacamos várias redes de produtores mobilizados em torno da Agroecologia ou produção de orgânicos) e agricultores.

O momento de maior conflito abrangeu desde a época dos debates sobre o plantio ilegal de soja em 1999 no Rio Grande do Sul até a aprovação da Lei de Biossegurança em 2005. 0 foco principal de disputa estava nas possibilidades agrícolas que as sementes transgênicas trariam para a atividade no Brasil, tendo em vista que o plantio dessas sementes é uma realidade na maior parte dos países de economia fortemente agrícola ${ }^{3}$. Por outro lado, existiam e existem dúvidas em relação aos efeitos que esses produtos trazem à saúde humana e animal, e, principalmente, incertezas quanto aos impactos ambientais causados por esse tipo de plantio (para aprofundar o assunto, ver PORTO, 2005). No governo, o conflito se explicitou numa divergência acerca da competência entre a lei ambiental e a Lei de Biossegurança. Ou seja, quem deve deter o poder de decisão sobre o impacto dessa nova tecnologia, o Ministério do Meio Ambiente ou o Ministério de Ciência e Tecnologia?

No lado ambiental, a pressão era exercida pelas ONGs contra o Ministério do Meio Ambiente (MMA) de Marina Silva, pois, se esta não era uma bandeira (antitransgênicos) clara do MMA, havia um compromisso em não deixar que a liberação dos OGMs ficasse a cargo dos setores governamentais interessados na sua exploração econômica. Por outro lado, a demora do governo em assumir uma posição favorável aos transgênicos era apontada como prejudicial ao setor agroexportador e vista como uma tendência "verde" do governo (sobre isso ver SOLIANI, 2006). Em um encontro público com ambientalistas, a Ministra Marina Silva disse o seguinte: "Vocês podem acreditar na imprensa ou no que o Presidente Lula disse para mim. $O$ Presidente me garantiu que não assinará uma MP [Medida Provisória] liberando o plantio da soja transgênica" (SAFATLE; WEBER, 2004). Posteriormente, em 2003, o presidente Lula assinou a MP 113/03, convertida na Lei 10.688/03. 
A frase citada demonstra a intenção do MMA em não aprovar a liberação dos transgênicos e também demonstra a dupla atuação do Presidente, que, ao mesmo tempo em que se comprometeu com a Ministra Marina Silva, permitiu a venda e o plantio da soja transgênica por meio de medida provisória e depois enviou projeto para aprovação da Lei de Biossegurança, que regulamenta os transgênicos e tira a competência de liberação do MMA. Assim, o Congresso tramitou, de meados de 2002 até março de 2005, a nova Lei de Biossegurança. Apesar de alguns vetos, a Presidência da República sancionou a lei que trouxe a vinculação e a autoridade da CTNBio para OGMs (Organismos Geneticamente Modificados).

A Lei de Biossegurança, sancionada em 2005, acabou com a necessidade de licença ambiental para estudos e uso de OGMs, desvinculou a temática do MMA transmitindo à CTNBio (instância técnica ligada ao MCT) a competência exclusiva para julgar os pedidos de liberação para uso comercial de sementes transgênicas, e criou o CNBS (Conselho Nacional de Biossegurança), formado por 11 ministros e presidido por Dilma Rousseff. O CNBS foi projetado para ser uma instância superiora de decisão sobre o tema, mas nunca foi ativado. Na prática, quem aprova ou não os transgênicos é a CTNBio. A composição dessa comissão é dada pela presença de um representante de cada Ministério e especialistas de diversas áreas ligadas aos temas (saúde, meio ambiente, biotecnologia, agricultura familiar, defesa do consumidor etc.), e há a exigência de doutoramento para participar. Ressaltamos que esta Comissão concentra substancial parte da polêmica em relação aos transgênicos no Brasil, porque emite pareceres conclusivos no que tange à liberação desses organismos sem passar por outros órgãos do governo e/ou pela sociedade civil; e, além disso, mesmo que a reunião seja aberta a outros participantes, estes não têm poder de voto.

No processo de regulamentação da lei, o MMA consegue incluir a exigência de que os produtos transgênicos com uso comercial só pudessem ser aprovados mediante 2/3 dos votos na CTNBio. Em função do baixo quorum de comparecimento nas reuniões de aprovação, a regra dos $2 / 3$ acabava determinando que grupos minoritários mobilizados, contrários à aprovação conseguissem impedir a aprovação do produto. A regra dos 2/3 que acabou garantindo atraso e até a não liberação dos transgênicos naquele período inicial, logo foi identificada como entrave ao processo e, 
no momento em que o executivo encaminhou ao Congresso uma medida provisória que regulamentava do plantio de transgênicos no entorno de parques e reservas, os interessados na rápida aprovação dos transgênicos aproveitaram a abertura de discussão da lei para modificar o quorum para $50 \%$ mais 1 . Os seguintes trechos de entrevistas falam sobre o peso dos votos para aprovação dos transgênicos e sobre a dificuldade de acesso das organizações às decisões da CTNBio: ${ }^{4}$

Isso se radicalizou quando no fim do ano passado, a CTNBio reprovou, deixou de aprovar, uma licença para vacina transgênica para suínos por 17 votos a 4.17 a favor e 4 contra e os 4 que eram contra barraram a aprovação porque faltava 1 voto para 2/3. Em função disso, o Congresso Nacional enfiou lá um negócio de diminuição do quórum e passou o quórum para $50 \%$ mais 1. Então, agora muitas coisas que não estavam sendo aprovadas, estão sendo aprovadas, muitas com voto contrário do setor ambiental, do pessoal que e mais crítico com relação aos transgênicos (Secretário executivo do MMA 2003-2007).

Na verdade, as organizações não têm assento (na CTNBio). Os assentos são dos ministérios e eu acho que têm uma organização. Eu sei que, por exemplo, na área ambiental o que a gente tinha eram pesquisadores, que tinham uma série de pré-requisitos, o cara tem que ter doutorado e tal... Então isso já restringe muito a possibilidade de participação e são indicações que as ONGs fazem para os ministérios, e os ministérios indicam (Diretora do ISA - Instituto Sócio-Ambiental).

A questão dos transgênicos envolve setores importantes e influentes politicamente no país e no mundo. 0 Brasil tem como uma forte base econômica a agricultura de exportação; consequentemente, o setor do agronegócio é muito influente tanto no Ministério de Agricultura quanto no parlamento - é de notório conhecimento a formação da bancada ruralista com ativo desempenho no Congresso Nacional ${ }^{5}$. Mas, a esse setor econômico, soma-se aquele ligado à tecnologia, que se desenvolveu amplamente nas últimas décadas no campo da agricultura e tem alterado profundamente as formas de produção em larga escala, tornando este campo extremamente competitivo na comercialização mundial de grãos.

As mudanças de competência decorrentes da lei de biossegurança sancionada, passando para a CTNBio a autoridade na liberação dos trans- 
gênicos, somado ao caráter centralizador que não permite a participação das organizações ambientalistas em tal comissão, levaram a um clima de conflito e tensão em torno dos "especialistas" em biossegurança e os ambientalistas. De forma concreta, o conflito em relação aos transgênicos levou a um episódio de confronto físico, em uma reunião da CTNBio, entre setores da sociedade civil e do Estado posicionados de formas diferentes. Neste conflito torna-se evidente a aproximação entre organizações, Ministério Público e Ministério do Meio Ambiente. 0 ocorrido estava relacionado à não-autorização, por parte dos integrantes da CTNBio, de que pessoas do Greenpeace e da ASPTA permanecessem assistindo à reunião que estava por se encaminhar naquele momento. A reação dos integrantes destas organizações foi de permanência, e o conflito culminou com a presença da polícia para a retirada dessas pessoas do recinto.

No "tumulto", os representantes do MMA, do Ministério do Desenvolvimento Agrário e do Ministério Público se posicionaram favoráveis às organizações ambientalistas. Na oposição estavam: um representante do Ministério de Desenvolvimento, Indústria e Comércio Exterior; um especialista em saúde humana; um especialista da área vegetal; um especialista em biotecnologia; um representante do MCT; o Presidente da CTNBio. Como desfecho, foi instaurado um inquérito civil público, e uma liminar da justiça federal de Brasília garante até o momento que as reuniões da CTNBio devem ser abertas ao público em geral (MINISTÉRIO DA CIÊNCIA E TECNOLOGIA, 2007). A seguir, podem ser vistos alguns trechos dos depoimentos da discussão travada durante a reunião na qual houve o conflito (MINISTÉRIO DA CIÊNCIA E TECNOLOGIA, 2007):

O Ministério Público já está estudando esse assunto e, certamente, se a posição da CTNBio hoje for no sentido de vetar ao público o acesso às reuniões, nós faremos recomendações, nós entraremos com medidas judiciais cabíveis. Eu acho que é um abuso de autoridade mandar que as pessoas se ausentem, considerando que eu falei inicialmente. Então, eu gostaria de sensibilizá-los no sentido de que nós estamos defendendo a ordem democrática, a lei e a Constituição do país. (Procuradora do Ministério Público Federal - 2007).

[...] nós temos um compromisso de sigilo com o proponente -, seja empresa, universidade, instituição pública -, então nós estamos também 
precisamos saber como é que fica isso. E qualquer decisão que nós tomemos, nós teremos que, primeiro, nós decidirmos o que vamos fazer antes da entrada de pessoas estranhas aqui dentro. (Representante do Ministério do Desenvolvimento, Indústria e Comércio Exterior - Titular).

[...] nós estamos exercitando, me permita a discordância com V.Exa direito de cidadania, o direito de acessar um espaço público que é este espaço, é um espaço público para acompanhar uma votação de interesse público, a questão dos transgênicos não é uma questão apenas técnica, Sr. Presidente, os impactos que essa questão têm sobre toda a sociedade brasileira, os impactos são muito grandes e dizem respeito a todos nós, a todos os cidadãos e a todas as cidadãs que aqui estão. [...] Não há nada que possa ser decidido aqui, a não ser que haja algum interesse subalterno, que eu quero crer que não há, Sr. Presidente, que eu quero crer que não há nenhum interesse subalterno, a não ser que haja um interesse subalterno, essas questões deveriam ser de conhecimento de todos que são as pessoas que vão consumir querendo ou não, o que os senhores e as senhoras vão aprovar e liberar aqui. (Representante do Greenpeace).

É interessante notar a posição do Ministério Público em defender a permanência das organizações na reunião. De modo geral, chama a atenção o comentário de que o Ministério Público é participante da CTNBio graças à exigência feita pelo MMA. Os outros integrantes não consideravam isso necessário e tampouco desejável. Além disso, o que se observa nos trechos transcritos é que, aparentemente, o conflito está entre uma posição de resguardar o sigilo comercial $^{6}$ da empresa proponente e o interesse público manifesto nas palavras do representante do Greenpeace, em ter acesso aos processos de aprovação do cultivo de sementes transgênicas, tendo em vista o direito do consumidor de saber o teor dos produtos que consome.

Sobre o conflito ocorrido nesta reunião, a Procuradora escreveu nota à impressa em nome do Ministério Público Federal onde diz: “O episódio, de hoje pela manhã, ao nosso sentir, foi o mais deplorável e lastimável que pude registrar em mais de 16 anos de atuação como representante do Ministério Público Federal, tendo em vista o abuso de autoridade por parte da Presidência da CTNBio." E além disso comenta: 
Nos causou constrangimento a forma como o sr. Colli tratou a questão toda, inclusive ameaçando retirar os representantes da sociedade civil com uso de força policial [...] As reuniões da Comissão são públicas e o direito de acesso a elas está garantido na Constituição.(GREENPEACE, 2008).

Ponto interessante que levanta o tema dos transgênicos é a articulação da luta em torno do direito do consumidor, evidentemente, que estimulado pelos instrumentos institucionais de proteção aos direitos difusos aos quais se insere. Contudo, é importante notar o deslocamento que a resistência antitransgênicos realiza de um discurso centrado na proteção ou precaução ambiental para um discurso que articula esta dimensão com os direitos dos consumidores ao meio ambiente preservado, à saúde humana e ao poder de escolher ou não comprar um produto transgênico ${ }^{7}$. Podemos pensar que talvez quando se trata de contrapor-se aos interesses econômicos a forma de oposição que encontra mais força é aquele que projeta o interesse de um ator que faz todo o sentido na própria lógica econômica: o consumidor. Entretanto, isto não minimiza a problemática. Outro aspecto dessa problemática no que se refere ao direito do consumidor argumentado pelo representante da ONG, encontra-se no fato de que a população em geral pouco sabe acerca desse assunto e, em sua maioria, desconhece o significado exato do termo "transgênico". Assim, consequentemente, a população fica alijada das discussões engendradas por canais públicos ou pela mídia sobre o tema. Em pesquisa de abrangência nacional de 2001 feita pelo Ibope por encomenda do Greenpeace, $66 \%$ dos entrevistados nunca ouviram falar em "organismos transgênicos" (IBOPE - Pesquisa de Opinião Pública Transgênicos, 2001).

Segundo Guivant (2006), há uma tendência no Brasil em não levar à população debates que são considerados de caráter científico. Isso se revela, inclusive, na falta de iniciativas de pesquisas de opinião acerca de temas como esse. 0 contraste disso é a constante preocupação em realização de pesquisas de avaliação da população sobre o uso de novas tecnologias na Europa e nos EUA - inclusive no caso dos OGMs. ${ }^{8}$

Dessa forma, além dos interesses comerciais, agrícolas e ambientais envolvidos nessa discussão, a temática dos transgênicos envolve uma dimensão ainda mais complexa: está diretamente vinculada à área 
da ciência e tecnologia. Ou seja, apesar de serem decisões com claras intenções econômicas e consequências para a sociedade, as discussões não envolvem protagonismos do mercado e do interesse público, mas do avanço da ciência ${ }^{9}$. Nos debates, os interlocutores que dialogam com a sociedade civil não são os agroexportadores, nem os empresários, são os cientistas que protagonizam esse embate. Nesse ponto, o conflito se torna mais agudo, uma vez que no lado pró-transgenia está o argumento do progresso da ciência, do avanço de tecnologias que melhoram a vida do ser humano. 0 principal argumento da biotecnologia é que ela pode acabar com o problema da fome no mundo; entretanto, é impossível deixar de notar que as modificações genéticas produzidas estão mais relacionadas ao interesse próprio das commodities agrícolas. Importante notar que se do lado contrário aos transgênicos há um deslocamento discursivo na luta das razões da precaução ambiental para o direito dos consumidores, parece que rapidamente o grupo favorável aos transgênicos articula sua posição não somente no campo das explicações econômicas, mas do mérito da validade científica. Contra este, conforme notamos na fala da representante do Instituto Socioambiental, é mais difícil construir resistência visto que se trata de uma esfera de difícil acesso.

O que acontece, então, é que, mesmo existindo os interesses comerciais e econômicos em torno dos OGMs, o jogo de interesses foi deslocado para o terreno não do uso da tecnologia, mas do desenvolvimento dela enquanto objeto científico. Dessa forma, esses interlocutores falam no lugar do "suposto saber" da ciência, usando argumentos técnicos, trazendo dados e publicações; vêm embasados por instituições de pesquisa universitárias etc. 0 caso da CTNBio é emblemático na medida em que só podem fazer parte como membros da comissão pessoas que possuírem o título mínimo de doutorado. Do outro lado, no caso da ASPTA e do Greenpeace, estão agricultores, ambientalistas e profissionais cuja maior ameaça para a liberação dos transgênicos não está nos argumentos ou contra-argumentos científicos propostos, mas na possibilidade de se constituírem como uma oposição de fato através do judiciário ${ }^{10}$ capaz de impedir, retardar os processos de liberação dessas sementes ou criar normas. Sobre essa questão fala Assessor Técnico da AS-PTA (Entrevista concedida em 2013), 
Tem coisas que ela [CTNBio] faz, e só faz, a partir de interpelações que fizemos na Justiça. Para dar um exemplo, naquela primeira liberação do milho transgênico da Liberty Link, da Bayer, a CTNBio não tinha sequer um protocolo interno de como avaliar um pedido de liberação comercial. [...] Não havia um regulamento para avaliar os vários aspectos, por exemplo, nos campos da Saúde, do Meio Ambiente... Era uma decisão individual e muito solta. Nós questionamos isso e o Judiciário entendeu que era necessário um protocolo para avaliar os pedidos e hoje em dia eles têm que desenvolver isso. [...] A mesma coisa para regras de isolamento. Como evitar, ou tentar evitar que um plantio de transgênicos não contamine o vizinho que é orgânico ou é agroecológico. Também não existia isso! Depois da liberação o Judiciário entendeu que precisa ter. Foi criada essa regra. Tem todo um debate sobre o sigilo da informação que ainda não está resolvido e que estamos debatendo na CTNBio e no Judiciário também. [...] Justiça foi que a CTNBio, ao aprovar o plantio comercial de qualquer produto, tenha que demandar da empresa um plano de monitoramento pós comercialização (Assessor Técnico da AS-PTA).

Isso nos interessa na medida em que pode revelar que, se por um lado ambientalistas perderam no jogo de forças políticas quando o executivo encaminhou a Lei de Biossegurança para aprovação do congresso, por outro lado ambientalistas conseguem fazer frente aos transgênicos por meio de outras estratégias políticas e contando, inclusive, com aliados no Estado: MMA, Ministério Público e setores do judiciário. Sobre a demora na decisão dos processos de liberação na CTNBio:

(Sobre os impactos das ações das ONGs no processo de liberação dos transgênicos): Tem prejudicado. Tem prejudicado porque se você fizer uma análise na pauta da CTNBio, você vê esses prejuízos claramente explicitados ali. Têm processos de 1 ano atrás. Enquanto que os ritos estabelecidos pela lei, dizem que os processos eles podem demorar no máximo, dentro da CTNBio, 120-180 dias desde o seu protocolo até o seu parecer final. Seja deferido, seja indeferido. Mas têm processos com um ano. No meu modo de ver isso é reflexo dessa divergência dogmática que tem se estabelecido na CTNBio (Coordenador Geral da CTNBio, grifo nosso).

Notamos, então, que as organizações buscaram uma forma de pressionar pelo seu interesse também em outras estruturas institucionais do Estado: o poder judiciário. No caso dos transgênicos, após o governo se posicionar favorável à Lei de Biossegurança, regulamentando o plantio de 
OGMs e retirando as discussões do campo ambiental, organizações passaram a buscar no poder judiciário uma forma de deter as licenças dadas pela CTNBio. Isto se intensificou pela ausência de espaço para participação da sociedade civil nas decisões da CTNBio e pelo antagonismo estabelecido entre aquilo que é considerado uma decisão técnica e científica que prescinde de participação e aquilo que é visto como militantismo ambiental. Abaixo seguem os depoimentos sobre a atuação no campo judicial:

Tem um outro tipo de atuação que é a luta judicial. As ONGs têm feito um contraditório, em alguns momentos com sucesso, na via judicial. Entrado com mil e uma solicitações de liminar e assim por diante. Recentemente eles têm conseguido. Decisão judicial eu já aprendi há muito tempo que não se discute. Mas, uma análise que faço é que em primeiro lugar os juízes ao concederem uma liminar têm pouco conhecimento de causa sobre aquilo em que eles estão se manifestando haja vista a última liminar que tem sobre o próprio milho LL (Coordenador Geral da CTNBio).

Isso é verdade em termos parciais [que as ONGs têm encontrado respaldo no poder judiciário], porque a gente conseguiu liminares que tinham, em determinado momento, cassado decisões adotadas pela CTNBio que liberavam a comercialização de espécies como o milho. Porque todas as formalidades que deveriam ter sido seguidas em relação a realização de estudos, quorum de audiências, chamamento de audiências públicas, tinham sido solenemente desobedecidas pela CTNBio. Ou seja, na pressa de fazer a coisa andar muito rapidamente - porque eles se comportam como órgão de fomento e não como órgão de Biossegurança - eles saem atropelando para fazer a coisa o mais rápido possível. E, aí se foi à justiça, se pediu liminares para esse fim. Só que essas liminares vêm sendo, por uma ação do governo, progressivamente cassadas na justiça. Até porque a CTNBio fez uma coisa profundamente autoritária e um dos secretários executivos do MCT o fez, que é dizer que a justiça não tinha competência para analisar as decisões da CTNBio. Nem a ditadura no Brasil nos anos 70 ousou dizer que a justiça não poderia examinar suas decisões. 0 que não existe! A justiça está lá como última instância, último recurso, de uma vontade que um cidadão possa manifestar de querer examinar qualquer decisão, seja de um particular, seja de órgãos do Estado. Mas, existe uma coisa muito autoritária dos promotores da transgenia que é querer revestir tudo o que eles fazem como se fosse ciência pura, como se não tivesse interesse comercial envolvido, para dizer que qualquer coisa que signifique contestar é um atentado contra a ciência (Diretor de Políticas Públicas do Greenpeace no Brasil, grifo nosso). 


\section{A luta judicial}

Se no lado dos pró-transgênicos existe o contexto de uma dimensão estrutural de atuação política bastante conhecida e com resultados já esperados; para alguns ambientalistas da sociedade civil contrários à transgenia a estratégia que se mostrou mais eficaz foi a atuação judicial já que a pressão direta no executivo através dos canais de participação não ultrapassou os limites do Ministério do Meio Ambiente.

Ao violar a legislação inicial (antes da aprovação da Lei de Biossegurança de 2005) e não submeter suas pesquisas ao licenciamento ambiental do IBAMA, a empresa Monsanto fez uma aposta no lobby parlamentar. Sua estratégia previa a ação parlamentar junto à chamada "bancada ruralista" e uma aposta na previsibilidade de mecanismos de ação operantes entre executivo e legislativo (FIGUEIREDO; LIMONGI, 1999). Assim, atingiram seus objetivos mais urgentes.

Além dessa, ainda houve outra estratégia para a aprovação da Lei de Biossegurança. Essa estratégia consistiu na vinculação de dois assuntos polêmicos e que despertavam posições contraditórias: o uso de células-tronco para pesquisas em medicina e o uso de transgênicos na agricultura. 0 atrelamento dos dois implicava a derrota ou a aprovação absoluta dos dois. Na própria sociedade civil havia uma grande mobilização a favor da aprovação das pesquisas e do uso de células-tronco. A amarração dos dois temas foi uma estratégia conjunta de setores agrários e setores tecnológico-científicos.

Contudo, apesar do processo de liberação dos transgênicos ter representado uma perda para organizações da sociedade civil, a constante oposição através de ações judiciais do Ministério Público e de organizações ambientalistas tem prejudicado o processo de liberação destes, atrasando sua comercialização. Dessa forma, apesar de as organizações não terem conseguido influenciar a tomada de decisão política que criou a Lei de Biossegurança, elas têm conseguido alguns resultados por meio de um outro tipo de atuação a "luta judicial".

Em termos numéricos, a busca por ações judicias abertas de 1998 a 2012 retornou um total de 28 litígios envolvendo OGMs, sendo que 
71,4\% (20 casos) foram ACPs, 25\% (07 casos) foram Adins e 3,6\% (01 caso) foi o que o judiciário brasileiro chama de Ação Coletiva. Além disso, $28,6 \%$ (08 casos) foram encontrados no STJ, 21,4\% (06 casos) no STF, $39,3 \%$ (11 casos) no TRF1 e os outros 10,7\% (03 casos) são referentes a ações de outros tribunais.

0 tempo entre a abertura e a última decisão publicada do processo foi predominantemente menor do que quatro anos, com o total de 78,5\% dos casos: até um ano concentra $35,7 \%$ das ações; até quatro anos corresponde a $25 \%$; até dois anos representa $7,1 \%$ das ações; até três anos, cinco anos e mais de cinco anos representam, cada um, 10,7\% das ações. A justiça brasileira é conhecida pela morosidade nos processos judiciais. Pode-se perceber que quase metade dos casos levou mais de três anos para obter decisão, e desses, $10,7 \%$ se prolongaram por mais de cinco anos. 0 judiciário pode ser visto como uma arena privilegiada para a ação coletiva, mas, ainda aparece como recurso último nos repertórios de ação dos movimentos, pois, dentre diversas razões apontadas, lançar mão de recursos jurídicos costuma ser um processo lento, dispendioso e com resultados incertos.

Apesar dessas projeções, um aspecto positivo é que a maior parcela do tempo de decisão se concentrou em até um ano. Vale ressaltar, entretanto, que em muitas dessas ações ainda cabe recurso, o que pode acarretar em prolongamento do tempo de decisão e mudança desse quadro em análises posteriores. Em sintonia com a fala do Entrevistado 1, McCann (2010) diz que essas novas possibilidades do sistema judicial provocam demandas vindas de baixo, bem como, criam novas culturas jurídicas que passam a valorizar as partes mais vulneráveis. Entretanto, o resultado disso é um número de demandas que levam longos períodos até uma resolução. Ou seja, é um sistema forte, mas disfuncional quando se leva em conta a média dos cidadãos.

A seguir expomos duas tabelas: a primeira sobre os autores das ações judiciais e, a segunda, os réus. 


\section{Tabela 1 - Ação Judicial por Autor}

\begin{tabular}{ccc}
\hline Autores & Frequência & Proposta - Transgênicos \\
\hline Ministério Público Federal & $26,7 \%$ & Contra \\
Idec & $13,3 \%$ & Contra \\
Partido da Frente Liberal (PFL - & $10 \%$ & Favorável \\
atual Democratas - DEM) & & \\
Governador & $6,8 \%$ & Contra e Favorável* \\
Pessoa Física & $3,3 \%$ & Contra \\
Greenpeace & $3,3 \%$ & Contra \\
Conselho Administrativo de & $3,3 \%$ & Não se aplica \\
Defesa Econômica (CADE) & & \\
Executivo Estadual & $3,3 \%$ & Contra \\
Empresa Brasileira de Pesquisa & $3,3 \%$ & Favorável \\
Agropecuária (EMBRAPA) & & \\
Associação Brasileira das Indús- & $3,3 \%$ & Favorável \\
trias de Alimentos (ABIA) & & \\
Partido dos Trabalhadores & $3,3 \%$ & Contra \\
Sindicatos Rurais & $3,3 \%$ & Não se aplica \\
Não encontrado/Outros & $16,6 \%$ & Contra \\
\hline TOTAL & $30 * *(100 \%)$ & \\
\hline
\end{tabular}

Fonte: elaboração própria baseada na análise das ações judiciais pesquisadas. *Contra: ex-governador Roberto Requião. Favorável: ex-governador do Mato Grosso

**0 número de autores é maior do que o número de casos, porque algumas ações possuem mais de um autor

\section{Tabela 2 - Ação Judicial por réu}

\begin{tabular}{cc}
\hline Réus & Frequência \\
\hline União Federal & $23,5 \%$ \\
Monsanto & $14,7 \%$ \\
Governador & $14,7 \%$ \\
Outras transnacionais de transgênicos* & $11,6 \%$ \\
Pessoa(s) Física(s) & $11,8 \%$
\end{tabular}




\begin{tabular}{cc}
\hline Réus & Frequência \\
\hline Legislativo Estadual & $5,9 \%$ \\
Executivo Estadual** & $5,9 \%$ \\
FHC & $2,9 \%$ \\
Não encontrado/Outros & $8,8 \%$ \\
\hline TOTAL & $34(100 \%)^{* * *}$ \\
\hline
\end{tabular}

Fonte: elaboração própria baseada na análise das ações judiciais pesquisadas. *Todas as outras grandes corporações da indústria biotecnológica de OGMs que foram rés, as quais são: Dow Agrosciencies Industrial Ltda, Avantis Seeds Brasil Ltda, Bayer SA e Bunge SA.

**No Executivo Estadual o réu é o Estado, n categoria Governador a ação é aberta diretamente contra o líder do executivo.

***0 número de réus é maior do que o número de casos, porque algumas ações possuem mais de um réu.

A partir dessas informações, podemos compreender a União como pró-transgênicos devido aos casos de omissões na cobrança da legislação ambiental, o que pode ser interpretado como incentivo a esses cultivos, e ao lobby da bancada ruralista. Prova disso é que cinco das oito ações abertas pelo MPF foram impetradas contra a União Federal, que por sua vez é ré em oito ações judiciais. Outros réus relevantes são as grandes transnacionais de desenvolvimento de OGMs, das quais se destaca a Monsanto. São dados que corroboram com as disputas socioeconômicas, políticas e científicas em torno dos transgênicos, os quais já tratamos de maneira breve.

Vale dizer que os estados do Rio Grande Sul e do Paraná são os locais de maior abertura de processos no tema dos transgênicos, correspondendo a 46,6\% dos casos, contra os 33,4\% de conflitos sem estado específico e $20 \%$ espalhados em alguns dos demais estados. A priori, pode não parecer surpresa que os conflitos se concentrem, predominantemente, na área em que haja grande presença de cultivos transgênicos e se ausentem em locais em que não há esse tipo de organismo. No entanto, é interessante notar que na região Centro-Oeste do Brasil, importante celeiro agrícola nacional, com imensos cultivos de soja e outras espécies transgênicas, não geram muitas ações judiciais envolvendo transgênicos, sendo os dois processos que aparecem favoráveis aos OGMs. 
Para maior compreensão desses conflitos, elaborou-se a tabela 3. As categorizações foram feitas após a leitura individual dos processos, tendo como critérios os tipos de conflitos envolvidos nas ações. 0 aspecto motivacional central da ação é tido como "Conflito Principal", ou seja, o objeto que justifica a abertura e norteia o eixo central da ação judicial. Já a coluna "Múltiplos Conflitos" envolve o conflito principal, e outros conflitos de importâncias diversas existentes em tais processos. Escolheu-se abordar as demais motivações das ações para que dados substanciais na compreensão do ativismo judicial não fossem perdidos. Um exemplo emblemático é o da rotulagem, ligado às "Questões do Consumidor", que está presente em cinco ações, mas, em apenas uma é o conflito principal.

Tabela 3 - Ação Judicial por tipos de conflitos

\begin{tabular}{ccc}
\hline TIPO* & Conflito Principal & $\begin{array}{c}\text { Múltiplos } \\
\text { Conflitos** }\end{array}$ \\
\hline Questões Ambientais & $39,2 \%$ & $37,8 \%$ \\
Questões do Consumidor & $7,2 \%$ & $17,8 \%$ \\
Questões Comerciais e de Mercado & $17,9 \%$ & $8,5 \%$ \\
Questões de Atos do Estado & $3,6 \%$ & $3,4 \%$ \\
Questões Jurídicas & $32,1 \%$ & $32,7 \%$ \\
\hline TOTAL & $28(100 \%)$ & $58^{* *}(100 \%)$ \\
\hline
\end{tabular}

Fonte: elaboração própria baseada na análise das ações judiciais pesquisadas. *Questões ambientais: ausência de estudos ambientais; crime ambiental; princípio de precaução; agrotóxicos; direito ambiental. Questões do consumidor: rotulagem; propaganda enganosa; direito do consumidor; danos morais. Questões comerciais e de mercado: lei antitruste; importação ilegal; falsificação de documentos; propriedade intelectual. Questões de atos do estado: ausência de fiscalização; ausência de RET (Registro Especial Temporário). Questões jurídicas: conflito de competência; inconstitucionalidade. **Incluídos aqui os conflitos principais e os demais tipos de embates e argumentos. Logo, o total de conflitos é maior do que o número de ações.

Não é por acaso que muitas vezes os conflitos envolvendo transgênicos estão diretamente correlacionados às "Questões Ambientais". Losekann (2013) comenta que desde a democratização brasileira, na década de 1980, novas práticas e instrumentos de controle democrático têm 
surgido nas interações entre Estado e sociedade, citando o surgimento das ACPs e seu progressivo uso a partir de 1985. 0 direito ambiental no Brasil é composto tanto constitucionalmente, pelo artigo $\mathrm{n}$ - 225, como também através da Lei Federal no 6.938/81 que estabelece a Política Nacional de Meio Ambiente. 0 Ministério Público surge neste quadro como um forte ator na utilização de ACPs e defesas de direitos difusos e coletivos como os ligados ao meio ambiente.

Quase $40 \%$ dos conflitos principais e 37,8\% de todos os conflitos presentes nas ações judiciais são de ordem ambiental. A maior parte envolve a ausência de estudos ambientais (15,5\% do total de conflitos, presente em 09 casos), seguido pelo Princípio de Precaução (8,6\%, com 05 casos) e pelos agrotóxicos (6,9\%, em 04 casos). 0 caso dos agrotóxicos está fortemente ligado à parte das ações que criticam diretamente os cultivos da variedade transgênica de soja RR.

Já nos processos envolvendo “Questões Jurídicas”, e tendo em vista que $25 \%$ de todos os casos foram Adins, não é de se surpreender que tais conflitos ocupem o segundo lugar. Isso, porque além das Adins contabilizarem, evidentemente, sete casos de inconstitucionalidade, duas ACPs também possuem esse tipo de conflito. Além disso, o conflito de competência, também incluído dentro dessa categoria, aparece com relevo. Por se tratar de um vocabulário do universo jurídico, vale esclarecimento: competência é a "delimitação da área de atuação de cada juiz" (AMB, 2007, p.53), ou seja, a autoridade que cada juiz tem sobre dada região e certos tipos de julgamentos.

É um caminho predominantemente aberto por atores favoráveis aos transgênicos, porque há também a competência na legislação: a Constituição Federal de 1988 reparte as competências entre os entes federados e a União. Em outras palavras, cabe à União legislar sobre as normas gerais na maior parte dos casos, e a cada ente federativo legislar questões específicas dentro do traçado em plano nacional (MAFFRA,2012). E muitas vezes o Estado interferiu com leis ou ações de fiscalização para impedir o avanço dos transgênicos, o que levou à abertura de ações judiciais também pelo pólo favorável aos OGMs contra o executivo e/ou o legislativo estadual. 
Esses conflitos são recorrentes em 10 casos, num total de 17,2\% dos $32,7 \%$ de todas as ações que envolvem essa categoria. Estão incluídas aqui ações que se encaixam em ambos os tipos de conflitos de competência. Os que se encaixam no segundo tipo, comentado no parágrafo anterior, são relativos a uma ação do Partido dos Trabalhadores contra o ex-presidente Fernando Henrique Cardoso (FHC) e aos processos entre o PFL (atual DEM) e o ex-governador do Paraná, Roberto Requião, que se podem enquadrar como conflitos políticos em processos abertos pelo pólo favorável aos transgênicos.

Os demais conflitos de competência podem ser encaixados no primeiro caso supracitado e envolvem, na verdade, uma discussão entre autoridades judiciárias sobre a decisão ou não sobre conflitos, em que ambas se julgam incompetentes ou competentes para decidir os casos em questão; sendo, portanto, questões estritamente jurídicas, não envolvidas, ao menos neste ponto, diretamente com os transgênicos.

0 terceiro tipo de conflito mais recorrente se refere às "Questões do Consumidor", que compreende casos como os de propaganda enganosa, danos morais e o direito do consumidor de maneira mais ampla. Entretanto, o que mais chama atenção é a rotulagem dos alimentos transgênicos, que está presente em 8,6\% dos múltiplos conflitos, envolvendo cinco ações com os seguintes autores: duas Adins, uma aberta pelo governador do Mato Grosso e outra pelo antigo PFL contra a rotulagem presente na legislação paranaense contra os transgênicos; uma aberta pelo MPF, exigindo da União e da Bunge S/A a rotulagem de produtos que contenham esses organismos; e, duas com o Idec, uma delas em que o MPF é co-autor, exigindo a rotulagem.

Com relação aos proponentes da ação, é importante destacar que parte das organizações que ingressaram elas próprias com ações (IDEC - Instituto de defesa do consumidor e a Terra de Direitos ${ }^{11}$ ) possuem em seu quadro organizativo uma equipe de advogados. A outra organização que aparece, Greenpeace, realiza uma denúncia ao Ministério Público em São Paulo, justamente por não contar com equipe jurídica no Brasil. Dessa forma isso sugere que a capacidade da organização em manter uma estrutura jurídica é fundamental para que elas próprias possam ingressar com a ação. 
O caso dos transgênicos permite que se observe a forma como uma organização ambientalista da sociedade civil constrói suas demandas endereçando-as através dos diversos espaços participativos abertos à sociedade civil (conselhos, conferências, audiências públicas, etc) - ou mesmo através da pressão direta sobre as lideranças - ao poder executivo, principalmente ao Ministério do Meio Ambiente. Mas, na ausência de efetividade dessa demanda, uma vez que ela se restringe ao referido Ministério, ela passa a ser reformulada e re-encaminhada desta vez ao judiciário. As reivindicações passam a operar no campo da lei, evocando um direito e princípio ancorado na constituição. Aqui as organizações passam a se valer do aparato institucional a partir do qual suas reivindicações ganham espaço tanto pelo próprio texto constitucional quanto pela adesão dos juristas à causa.

Neste sentido, vale analisarmos alguns aspectos da posição estratégica que o poder judiciário ocupa no pensamento das organizações e ao mesmo tempo observar alguns mecanismos institucionais que permitem e balizam essa referida prática como a "judicialização dos conflitos ambientais".

Vários trabalhos no campo das ciências sociais nas últimas décadas (alguns deles: ARANTES, 1999; VIANNA, BURGOS e SALLES, 2007; VILLELA, 2009; CARVALHO, 2004; MACIEL e KOERNER, 2002) têm apontado para o papel que o Ministério Público adquiriu desde os anos 1980 - sendo marco da sua consolidação a Constituição de 1988 - como protagonista na defesa de direitos difusos e coletivos destacando-se direitos sociais, direitos humanos, meio ambiente, e ainda, sua capacidade de accountability. Assim, as organizações da sociedade civil engajadas na defesa pelo meio ambiente encontraram no Ministério Público um contundente aliado dotado de mecanismos institucionais capazes de interferir através de instrumento jurídico em questões previamente decididas nos espaços políticos institucionais do executivo e legislativo.

Segundo Arantes (1999) o Ministério Público se constituiu como o principal agente na defesa dos direitos coletivos canalizando conflitos desta ordem para o âmbito judicial. A Constituição de 1988 é um marco importante da consolidação tanto dos direitos difusos quanto das formas 
de controle judicial para a promoção desses direitos. É nesse momento que o Ministério Público ganha autonomia saindo da alçada do executivo. Além disso, o meio ambiente é o tema inaugural da normatização dos direitos difusos através da Política Nacional de Meio Ambiente de 1981. Destacamos aqui dois novos instrumentos legais: a legitimidade do Ministério Público na proposição de ação de responsabilidade civil e criminal por danos ao Meio Ambiente; e a ação civil pública que, além do Ministério Público, pode ser promovida pela União, estados e municípios, autarquias, empresas públicas, fundações e sociedades de economia mista e, com destaque para o nosso propósito, associações com mais de um ano de existência e que incluam a proteção ao meio ambiente, ao consumidor e/ou patrimônio histórico e cultural entre suas finalidades.

Arantes chama a atenção que as associações usam pouco o recurso da ação civil pública de forma direta, dando preferência à representação junto ao Ministério Público para que este promova a ação. A pesquisa realizada pela ONG ISA - Instituto Sócioambiental entre os anos de 2003 e 2005 sobre as ações civis públicas ambientais em curso ou julgadas pelo Supremo Tribunal Federal, Superior Tribunal de Justiça e Tribunal Regional Federal 1a região em Brasília (RELATÓRIO DE CUMPRIMENTO DO OBJETO, 2004) confirma essa ideia de que as associações usam pouco este instrumento. Notamos que apenas $5 \%$ das ações são propostas diretamente por associações. Contudo, é interessante notar que no caso dos transgênicos há uma maior atuação direta das ONGs, apesar de se manter uma forte iniciativa do Ministério Público.

Arantes (1999) sugere que a judicialização da política, como a transferência de conflitos de interesse da política para a justiça, pode ser operacionalizada a partir de duas perspectivas, 1-) pela existência de um quadro institucional que permite o transito da ação política para os tribunais; 2-) pelo ativismo judicial propriamente dito no que se refere à disposição dos atores da esfera judiciária em trazer para esta esfera discussões que estavam restritas ao campo da política. No entanto, uma outra chave analítica pode ser mais profícua para a compreensão do processo de litigância acerca dos transgênicos, qual seja, a abordagem da legal mobilization (VANHALA, 2012, HILSON, 2012). A adoção do lití- 
gio estratégico como parte do repertório de ação coletiva pode ocorrer, entre outros aspectos em função de "janelas de oportunidades políticas e legais" tais como: os canais institucionais jurídicos criados a partir de 1981, entre eles o uso das medidas liminares entre outras inovações institucionais já menciondas (LOSEKANN, 2013). Outro aspecto está na disposição dos juízes em serem favoráveis às causas ambientais, como notamos através dos dados do ISA e da disposição para decisões favoráveis notadas nos próprios casos dos transgênicos. Segundo Engelmann (2006) desde 1990 é possível notar um incremento do ativismo judicial brasileiro formado por redes formais e internacionalizadas ligadas a temas como a proteção ambiental, entre outros, articulados por ONGs e movimentos organizados cujo mote está na denúncia. Esse novo padrão de engajamento nas causas coletivas no Brasil passa pela junção entre o discurso militante, a expertise presente nos movimentos e soma-se também a profissionalização do advogado de movimentos sociais.

Para Lobato (2001) a judicialização também ocorre como recurso democrático último tanto para a sociedade civil quanto para a oposição quando se busca antagonizar alguma política governamental. Mas esse processo de judicialização denota também um processo de transferência das demandas políticas dos canais representativos para o judiciário, no caso ambiental. Segundo Vianna, Burgos e Salles (2007) a judicialização decorre justamente da incapacidade ou debilidade das instituições republicanas brasileiras em representar os interesses da sociedade civil. Tal debilidade traz o efeito da representação funcional que ocorre através da justiça pelos instrumentos criados progressivamente na década de 1980 até a normatização do código de defesa do consumidor em 1990. Neste sentido o juiz assume um lugar estratégico de interlocução com a sociedade civil como protagonista na tomada de decisão em questões sociais.

No que se refere especificamente à ação civil pública, Vianna e Burgos (2005) sugerem que a mesma se torna uma forma de controle da sociedade civil sobre as instituições que não operam em seu interesse. Entretanto, este caráter inclusivo ao qual pode estar associado à ação civil pública é paradoxalmente restritivo na medida em que demanda conhecimento técnico jurídico para sua instrumentalização. Ou seja, a 
associação precisa saber da existência desse instrumento legal, contar com conhecimento jurídico e advogados para realizar tal ação. Nesse sentido vale lembrar que entre as organizações citadas no caso dos transgênicos, aquelas que ingressam diretamente com ACP são as que possuem quadro de advogados na sua estrutura.

Em análise acerca de alguns casos de ação civil pública, Vianna e Burgos sinalizaram certos aspectos encontrados referentes à temática ambiental os quais são relevantes para nossa análise. 0 caso relativo ao tema ambiental trata-se de um Termo de Ajustamento de Conduta envolvendo a localidade de Ilha Grande no RJ assinado em 2002. A promoção do Termo é de prerrogativa do Ministério Público e ocorre como um procedimento pré-processual justamente para evitar a judicialização do conflito. No referido caso o objeto do Termo seria estabelecer o compartilhamento de responsabilidades na gestão da Ilha com o objetivo maior de preservar o meio ambiente (VIANNA e BURGOS, 2005).

Contudo, o que é relevante para nós neste caso é o processo desde a mobilização da sociedade em suas organizações locais até a solução via Ministério Público. Desde 2000 a população vinha se mobilizando através de abaixo-assinados e pressão sobre a prefeitura para que esta respondesse às suas reivindicações pela melhor conservação do meio ambiente local. Os autores chamam a atenção por um lado, para a ineficácia da pressão sobre o executivo local; por outro, para a baixa penetração e representatividade das ONGs em relação a população local.

Assim, o Ministério Público assume o papel de propagar nas vias institucionais aquilo que surge como um problema social para certos grupos e que os representantes locais não identificam como uma questão social prioritária. Nesse sentido, por intermédio deste interlocutor privilegiado a via judicial torna-se a única via de ação. Os autores concluem em relação ao caso analisado que houve uma aliança entre ambientalistas e Ministério Público - da mesma forma como ocorre na nossa análise acerca dos transgênicos. Mas, até que ponto podemos dizer que a judicialização de temas ambientais no Brasil está significando a abertura de um canal para a participação da sociedade civil ou, de outra forma, relevando sua limitação? 


\section{Problematizando judicialização e participação a partir de uma leitura Habermasiana}

Araújo (2004) destaca que apesar de autores como Habermas tratarem da judicialização como juridificação no sentido de "colonização do mundo da vida por parte do sistema jurídico" esta pode também ser entendida como forma alternativa para a representação democrática.

Ocorre que segundo Habermas (2003), os direitos fundamentais expressos nas constituições como o núcleo dogmático de valores a serem preservados, são de incumbência especifica do Estado - única instância capaz de dar conta da sua aplicabilidade universal (COHEN e ARATO, 2000). Dessa forma a juridificação ocorreria pelo avanço regulatório do Estado nas esferas da vida dos sujeitos para além do núcleo dogmático o qual deve preservar - "colonizando o mundo da vida". Aqui o avanço da esfera jurídica é tomado como prejudicial e inibidor dos princípios de liberdade da sociedade civil.

No entanto, segundo Araújo (2004) no caso brasileiro o problema da judicialização se estabelece na lacuna entre as demandas da sociedade por direitos e a incapacidade das instituições representativas de garantirem a universalização dos mesmos. 0 judiciário tem entrado nesse vácuo como expectativa da sociedade de ter seus direitos concretizados. É neste sentido que o autor propõe a judicialização como uma forma de participação.

Desta forma, se por um lado a presença de instrumentos jurídicos para a resolução de conflitos pode significar uma forma de acesso da sociedade civil ao Estado na defesa de suas demandas, por outro lado, significa - como vimos através do caso dos transgênicos, a falência tanto dos meios representativos republicanos como sugerem Vianna, Burgos e Salles (2007), mas também, a carência de espaços de articulação discursiva entre a própria sociedade civil e entre esta e o Estado. No que tange as dinâmicas internas da própria sociedade civil, percebemos as dificuldades de reconhecimento mútuo entre setores representantes da ciência e da pesquisa em tecnologia e os segmentos ambientalistas. Aspecto que se torna contundente na recusa dos integrantes da CTNBio em aceitar a participação de representantes das associações civis nos debates de liberação dos OGMs. 
Neste sentido torna-se necessário avançar na própria conceituação da sociedade civil nos espaços nos quais está se faz representar. No caso da comissão que analisa os transgênicos, o espaço da sociedade civil foi projetado para ser ocupado por organização que trata dos direitos dos consumidores, o IDEC (Instituto de Defesa do Consumidor), o qual não participa por discordar dos procedimentos da comissão. Mas, outro aspecto que vale notar é que a rigor, tirando os representantes dos ministérios, todos os demais poderiam ser intitulados "sociedade civil" - são representantes de áreas do conhecimento: especialista na área vegetal, animal, saúde humana, etc. Entretanto, não estão presentes ali como representantes da sociedade civil mas, como técnicos. Aqui encontramos outra problemática: ao deslocar a discussão sobre transgênicos e a atuação da própria comissão para o campo da "técnica", acaba-se por deslegitimar a prática de participação como princípio de tomada de decisões e formação de consensos. Parte-se do princípio de que aquilo que é técnico está livre da política ${ }^{12}$, ou torna o debate político prescindível - afirmativa que pode facilmente ser questionada. Além disso, também gostaríamos de ressaltar que ainda é escasso o debate acerca do conceito de "sociedade civil" e suas implicações nos contextos do Brasil (BALLESTRIN \& LOSEKANN, 2013). ${ }^{13}$

Habermas, ao tratar da ciência e da técnica como forma de ideologia, aponta justamente que a racionalidade científica e técnica jamais pode subsumir à racionalidade típica da ação comunicativa (HABERMAS, 1986. p.106). Desta forma, nunca um argumento científico poderia eliminar uma discussão pública. $\mathrm{O}$ autor associa o campo jurídico ao domínio da técnica em contraposição a outro tipo de racionalidade discursiva própria do mundo da vida. Curioso é que no caso dos transgênicos o campo da ciência como monopólio de uma saber técnico e produtor de verdades está em outra esfera, no discurso dos cientistas e representantes do Estado que ocupam a CNTBio. Estes reivindicam para si a legitimidade de decisão baseada em um conhecimento específico do qual inclusive os magistrados estão excluídos. Assim, a temática do transgênico suscita mais um ponto de discussão: a criação de outras esferas de monopólio do "saber técnico" além daquela circunscrita ao campo jurídico como sugeriu Habermas. Significa a ilusão de resolução do conflito pelo estabelecimento de uma 
verdade cientifica. A proliferação das pesquisas nas áreas de biotecnologia acompanhadas da incorporação de suas descobertas na vida cotidiana do ser humano demandará certamente debates acerca do tratamento "apolítico" com o qual os governos têm tratado a questão ${ }^{14}$.

Ademais, o encaminhamento político do tema dos transgênicos observado anteriormente refletiu a incapacidade do governo de incluir a perspectiva daqueles que são cautelosos ou mesmo contrários ao desenvolvimento desses organismos. Da mesma forma, a criação de uma instância decisiva que não inclui a possibilidade de diálogo entre aqueles que fomentam e os opositores da transgenia organizados na sociedade civil também significa a exclusão do processo de grupos interessados neste tema. Entretanto, representantes de ONGs e movimentos também demonstram muita propensão ao conflito e pouca à busca de um consenso. Assim, o litígio estratégico ${ }^{15}$ entra como o recurso último daqueles que estão excluídos do processo de decisão política. .

$\mathrm{Na}$ fala do diretor do Greenpeace, já citado anteriormente (pg. 11 e 12 em negrito), a justiça também aparece como a última instância e também associada à ideia de revisão de decisões de outros poderes. Neste sentido, como aponta a bibliografia expressa anteriormente, trata-se mais uma vez da intervenção política de um poder jurídico. Entretanto, tomar essa judicialização como reflexo ou possibilidade de participação da sociedade merece cautela.

Segundo Habermas, o advento do direito positivo traz justamente a substituição da validade através da força pela validade através da lei. Ou seja, ao invés dos sujeitos buscarem suas realizações pela força (atributo que passa a ser prerrogativa do Estado), ganham uma autorização para ingressarem com uma ação judicial (HABERMAS. 1997. p. 48). Nesse sentido, vale destacar que na fala das organizações o recurso ao judiciário é equivalente ao recurso da força ("nem que seja pela força" nas palavras acima proferidas pela diretora da ONG). Entretanto, a referência Habermasiana da validade da norma jurídica está na ideia de Kant de legitimidade enquanto produto de racionalização (razão prática). Desta forma, o sentido da ação jurídica sugerido pela organização vai para o lado oposto à proposta habermasiana. Não opera como busca de reconhecimento de um direito que é fruto de um debate através da articulação discursiva, 
mas sim, opera como recurso que reflete a falência ou impossibilidade dos debates entre as esferas da sociedade.

Ocorre que, como notamos, o recurso judicial entra como último recurso na luta contra os transgênicos. Percebemos que antes de qualquer encaminhamento ao poder judiciário há tentativas e mesmo, expectativas de participar ou influenciar neste tema através dos representantes dessa causa no executivo e no legislativo. Aqui vale lembrar que a orientação antitransgênico foi explicitada pelos representantes da sociedade civil nas duas primeiras Conferências Nacionais de Meio Ambiente nas formas de deliberações que deveriam orientar a política ambiental. Além disso, as organizações mobilizaram-se para participar da CTNBio - espaço que lhes foi negado.

Alexandre (2000) vê na judicialização um perigo de certo autoritarismo jurídico. Nas suas palavras:

As representações valorativas conferidas pelas cortes de justiça e pelo Ministério Público na defesa de interesses sociais amplos ou de minorias (religiosas, grupos sociais marginalizados, ecologistas, homossexuais, deficientes físicos, velhos, jovens, etc.) interpõem também outro problema para a legitimidade de suas decisões. Vistas de modo teleológico, elas abalam os alicerces das normas, que passam a serem vistas como valores em si (ALEXANDRE, 2000 p. 11)

Segundo o autor, no Brasil, o processo que leva a interiorização das reivindicações dos atores da sociedade civil está mais ligado à normatização do que ao reconhecimento de valores - aspecto que fragiliza as conquistas. Além disso, ele sustenta que os direitos precisam ser sustentados e conquistados preferivelmente pela via legislativa a qual está projetada para esta função. No mesmo sentido, Bredariol também aponta o caráter autoritário das decisões judiciais a partir da análise de vários conflitos ambientais (BREDARIOL, 2004).

No entanto, como esperar de um legislativo com forte bancada ruralista o atendimento às demandas de parcelas da sociedade civil contrárias ao interesse desses parlamentares? Na análise das ações propostas no campo dos transgênicos e explicitadas anteriormente percebemos uma diferenciação no conteúdo das ações que dá novos desdobramentos 
para este argumento. Estamos nos referindo a importante função do Ministério Público Federal ao propor uma ação judicial visando garantir o direito de participação às organizações nas reuniões da CTNBio. Desta forma a ação do poder judiciário fica restrita a um caráter procedimental. Garantindo, ou protegendo as condições do procedimento democrático, mas sem interferir no conteúdo dos debates.

Cabe notar que a intervenção jurídica foi no sentido de garantir a participação e transparência nas reuniões da CTNBio. 0 judiciário teve um protagonismo que contribuiu para a preservação da autodeterminação política (HABERMAS, pg. 158. 2003b) da sociedade civil. Esse caso de legal mobilization poderia ser entendido como uma forma estratégica de garantir acesso de representação daqueles que não conseguem avançar com suas propostas através dos canais institucionais representativos. Deste modo, não toma a voz das organizações, mas garante espaço onde elas próprias possam se articular com autonomia em relação aos seus opositores.

\section{Considerações finais}

É importante notar que segundo nossa proposta vislumbrada pelo caso dos transgênicos, a ação judicial não surge descontextualizada e nem se constitui como o objetivo primeiro das organizações. Ao contrário, ela aparece no momento em que estrategicamente a organização esgota todas as suas apostas na ação nos espaços propriamente políticos. $\mathrm{Ou}$ seja, quando apesar de todo o seu empenho em mobilizar os esforços para a influência em determinadas políticas públicas, os resultados, ou são desfavoráveis, ou percebe-se que os setores institucionais do executivo e do legislativo são insensíveis aos seus apelos. Aqui, talvez o Ministério Público encontre um papel importante em advogar pela necessidade de transparência e acesso à sociedade civil nas decisões produzidas por estes dois poderes. Vale apontar também o caso das ONGs com quadro de advogados próprios que, apesar de não constituírem a maioria dos casos gerais, é bem relevante no caso dos OGMs.

Young nos relembra de uma frase interessante de Habermas (1990, p. 25 apud, (HABERMAS, 2003b, pg. 160,): “Os direitos têm a ver com o fazer, mais do que com o ter, portanto, com relações que autorizam a 
ação ou a exigem à força". Certamente este artigo não esgota a questão, ao contrário sugere várias. Futuras agendas de pesquisa no campo da judicialização ambiental precisam levar em conta 1) o grande nível de antagonismo nas disputas ambientais 2) a grande dificuldade que o campo do ambientalismo em geral encontra para ter suas demandas levadas em consideração quando os interesses econômicos estão em jogo. Esses dois aspectos sugerem que talvez nem mesmo a ética do discurso com suas práticas comunicativas asseguradas como gostaria Habermas sejam suficientes para suscitar o entendimento nos conflitos ambientais.

\section{Notas}

1 Sugerimos a leitura deste artigo para maiores esclarecimentos.

2 As principais empresas envolvidas nessa questão são Monsanto, Bayer e Embrapa.

3 Atualmente (2015) os Estados Unidos, Brasil e Argentina são os países que têm a maior área plantada de transgênicos no mundo. Fonte: (http://isaaa.org/resources/publications/briefs/49/ pressrelease/pdf/B49-PressRelease-Portuguese-Brazil.pdf).

4 Os depoimentos aqui mencionados são oriundos de entrevistas concedidas e realizadas com setores ligados à política ambiental, da sociedade civil, do governo, e da economia. As entrevistas foram semidirigidas levando em consideração as especificidades do setor do entrevistado.

5 Em 2011, um grupo de deputados da bancada ruralista sob o comando do deputado Aldo Rebelo conseguiu aprovar o novo Código Florestal que traz impactos diretos no desmatamento e amplia a área de agricultara no país.

6 Uma outra polêmica segue a partir de uma iniciativa da CTNBio na criação do "termo de confidencialidade" através do qual as organizações de público amplo não podem ter acesso aos projetos que estejam sob caráter de "confidencialidade". Fonte: http://aspta.org.br/campanha/ boletim-585-18-de-maio-de-2012/.

7 Aqui também está subjacente um debate em torno da segurança alimentar.

8 Cabe notar que, à exceção daqueles cientistas que desenvolvem essas tecnologias no meio acadêmico, o assunto não é amplamente tratado. 0 questionamento e monitoramento sobre os transgênicos tem ficado a cargo das organizações da sociedade civil, sobretudo ligadas à agroecologia e direitos do consumidor.

9 Sobre isso, ler Mariconda e Ramos (2003).

10 Isto não deixa de ser curioso, pois na oposição entre o saber técnico e o leigo, o judiciário está normalmente associado ao saber técnico. Neste caso o que ocorre é diferente, a decisão judicial é usada como instrumento de contraposição a outro saber técnico e por isso recebe grandes críticas dos cientistas envolvidos que acreditam que o judiciário não tem competência para julgar um aspecto que é na visão deles, estritamente técnico das suas áreas.

11 A maioria das ações abertas por estas ONGs encontram-se em tribunais e instâncias não analisadas pelas pesquisas.

12 Para discussões mais aprofundadas sobre ciência, transgênico, autonomia e princípio de precaução, ler Mariconda e Ramos (2003) e Lacey (2006).

13 A forma como tem sido compreendido e empregado o conceito gera diferenças e problemas importantes nas experiências concretas dos atores que ocupam posições de representação em espaços de decisão. Este não, contudo, o debate proposto neste artigo. Para uma discussão sobre o conceito de sociedade civil no contexto da Índia ver CHANDHOKE (2000).

14 Sobre o tema da cientificidade no campo da justiça ambiental ver: (PORTO e FREITAS, 2004)

15 O conceito de "litígio estratégico" foi desenvolvido por Harlow \& Rawlings (1992). 


\section{Referências}

ALEXANDRE, A. F. Questão de política como questão de direito. Cadernos de Pesquisa Interdisciplinar Em Ciências Humanas, Florianópolis, v. 13, 2000.

ALEXANDRE, A. F.; ANDREATA, Marjor; MINATTI, Márcio. Conflitos socioambientais e o papel do Ministério Público: o caso de Blumenau, SC, Brasil. Revista de Ciências Humanas (CFH/UFSC), Florianópolis, SC, p. 379-397, 2002.

ARANTES, Rogério Bastos. Direito e Política: O Ministério Público e a defesa dos direitos coletivos. Revista Brasileira de Ciências Sociais, v. 14, n. 39, 1999.

ARAÚJO, Gisele Silva. Participação através do direito: a judicialização da política. In: Congresso Luso-Afro-Brasileiro de Ciências Sociais. VIII., 2004, Coimbra, Anais...Coimbra, Centro de Estudos Sociais, Faculdade, Universidade de Coimbra, 2004. Disponível em: http://www.ces.uc.pt/lab2004/pdfs/GiseleSilvaAraujo. pdf. Acesso em: 15 dez. 2015.

ASSOCIAÇÃO DOS MAGISTRADOS BRASILEIROS. 0 judiciário ao alcance de todos: noções básicas de Juridiquês. 2. ed. Brasília: AMB, 2007.

BALLESTRIN, Luciana \& LOSEKANN, Cristiana. A abertura do conceito de sociedade civil: desencaixes, diálogos e contribuições teóricas a partir do Sul Global. Colombia Internacional, n. 78, p. 181-210, 2013.

BREDARIOL. Celso Simões. 0 aprendizado da negociação em conflitos ambientais. 2004. Disponível em: http://www.anppas.org.br/encontro_anual/ encontr o2/GT/GT17/gt17_celso_bredariol.pdf. Acesso em: 06 jul. 2009.

CARVALHO, Ernani Rodrigues de. Em busca da judicialização da política no Brasil. Revista de Sociologia e Política, n. 23, p. 115-126, nov., 2004.

COHEN, Jean L.; ARATO, Andrew. Sociedad Civil y Teoria Política. México: Fondo de cultura económica, 2001.

ENGELMANN. Fabiano. Internacionalização e ativismo judicial: as causas coletivas. Revista Lua Nova, São Paulo. 69, p. 123-146, 2006.

FIGUEIREDO, Argelina e LIMONGI, Fernando. Executivo e Legislativo na nova Ordem Constitucional. Rio de Janeiro: Editora FGV, 1999. 
FUKS, Mario. Relatos e Recursos Culturais: A Disputa em torno da definição do meio ambiente enquanto problema social no Rio de Janeiro. Revista Crítica de Ciências Sociais, Coimbra, v. 49, p. 157-188, 1997.

. Do discurso ao recurso: uma análise da proteção judicial ao meio ambiente do Rio de Janeiro. In: L. C. Ferreira e E. Viola (Orgs.). Incertezas de sustentabilidade na globalização. Campinas, SP: Unicamp, 1996.

GREENPEACE. Expedição 2004: Brasil melhor sem transgênicos .Disponível em: http://www.greenpeace.org.br/tour2004_ogm/?conteudo_id=3169\&sub_campanha=0). Acesso em: 01 ago. 2009.

GUIVANT, Julia S. Transgênicos e percepção pública da ciência no Brasil. Ambiente \& Sociedade, Campinas, v. 9, n. 1, 2006, p. 81-103.

HABERMAS, Jürgen. Mudança estrutural da esfera pública: investigações quanto a uma categoria da sociedade burguesa. Rio de Janeiro: Tempo Brasileiro, 2003a.

Direito e democracia: entre facticidade e validade. 2. ed. Rio de Janeiro: Tempo Brasileiro, 2003b. (v. II).

. Direto e democracia: entre facticidade e validade. Rio de Janeiro: Tempo Brasileiro, 1997. (v. I).

Ciência y técnica como “ideologia”. Tcenos: Madrid. 1986.

HARLOW, Carol; RAWLINGS, Richard. Pressure through law. Routledge, 1992.

HILSON, Chris. New social movements: the role of legal opportunity. Journal of European Public Policy, v. 9, n. 2, p. 238-255, 2002.

LACEY, Hugh. 0 Princípio de precaução e a autonomia da ciência. Scientle Studia, São Paulo, v. 4, n.3, p. 373-92, 2006.

LEITE, Marcelo. Arautos da razão: a paralisia no debate sobre transgênicos e meio ambiente. Novos estudos - CEBRAP, São Paulo, n. 78, 2007, p. 41-47.

LOBATO, Anderson Orestes Cavalcante. Política, constituição e justiça: os desafios para a consolidação das instituições democráticas. Revista de Sociologia e Política, Curitiba, n. 17, p-45-52, 2001. 
LOSEKANN, Cristiana. Mobilização do direito como repertório de ação coletiva e crítica institucional no campo ambiental brasileiro. Dados, p. 311-349, 2013.

MACIEL, Débora Alves e KOERNER, Andrei. Sentidos da judicialização da política: duas análises. Revista Lua Nova, n. 57, 2002.

MARICONDA, Pablo Rubén; RAMOS, Maurício de Carvalho. Transgênicos e ética: a ameaça à imparcialidade científica. Scientiae Studia, v. 1, n. 2, p. 245-61, 2003.

MINISTÉRIO DA CIÊNCIA E TECNOLOGIA. Comissão Técnica Nacional de Biossegurança - CTNBio. Degravação (Transcrição Ipsis Verbis) da 100a Reunião Ordinária da CTNBio: Tire suas Conclusões. 22 mar. 2007. Disponível em: <http://www.ctnbio.gov.br/upd_blob/0000/230.pdf>. Acesso em: 12 set. 2008.

PORTO, Marcelo Firpo. Riscos, incertezas e vulnerabilidades: transgênicos e os desafios para a ciência e a governança. Revista Política e Sociedade, Cidade, v. 4, n. 7, out., p. 77-103, 2005.

PORTO, Marcelo Firpo de Souza e FREITAS, Carlos Machado de. Discutindo o papel da ciência frente à justiça ambiental. II Encontro da Associação Nacional de Pós-Graduação em Ambiente e Sociedade (ANPPAS), Indaiatuba, SP, 26 a 29 maio 2004. Disponível em: http://www.anppas.org.br/encontro_anual/ encontro2 /GT/GT17/gt17_marcelo_porto.pdf. Acesso em: 06 jul. 2009.

RELATÓRIO DE CUMPRIMENTO DO OBJETO. Projeto “Banco de dados das Ações Civis Públicas Socioambientais na justiça Federal". Convênio MJ/ SDE/ FDD n. 001/ 2004. Convenente: Instituto Socioambiental.

SAFATLE, Amália e WEBER, Luiz Alberto. Marina Perde. Carta Capital, São Paulo, n. 313, p. 22, 20 out. 2004.

SOLIANI, André. 0 gene do atraso: primeira leitura. 49 ed. São Paulo, 2006. p. 54-59.

SORJ. Bernardo. A nova sociedade brasileira. 3 ed. RJ Jorge Zahar 2006.

VANHALA, Lisa. Legal opportunity structures and the paradox of legal mobilization by the environmental movement in the UK. Law \& Society Review, v. 46, n. 3, p. 523-556, 2012. 
VIANNA, Luiz Werneck. BURGOS, Marcelo Baumann; SALLES, Paula Martins. Dezessete anos de judicialização da política. Revista Tempo Social de sociologia da USP, v. 19, n. 2, p. 39-85, 2007.

VIANNA, Luiz Werneck e BURGOS, Marcelo Baumann. Entre princípios e regras: cinco estudos de caso da ação civil pública. Revista Dados: revista de ciências sociais, Rio de Janeiro, v. 48, n. 4, p. 777-843, 2005.

VILELLA, Patrícia. (Coord.) Ministério público e políticas públicas. Rio de Janeiro. Editora Lúmen Júris, 2009

Recebido em: 10-9-2015

Aprovado em: 20-10-2015

\section{Cristiana Losekann}

Doutora em Ciência Política pela Universidade Federal do Rio Grande do Sul (UFRGS); Mestre em Ciência Política pela Universidade Federal do Rio Grande do Sul (UFRGS); professora adjunta de Ciência Política da Universidade Federal do Espírito Santo (UFES).

E-mail: cristianalosekann@gmail.com

Universidade Federal do Espírito Santo, Centro de Ciencias Humanas e Naturais, Av. Fernando Ferrari, Goiabeiras, CEP 29075910 - Vitória, ES, Brasil, Telefone: (27) 40092506.

\section{Luiza Duarte Bissoli}

Mestranda do curso de Ciências Sociais da Universidade Federal do Espírito Santo (UFES); Especialização em andamento em Docência no Ensino Superior pelo Centro Universitário Senac (SENAC/SP); graduada em Ciências Sociais pela Universidade Federal do Espírito Santo (UFES).

E-mail: luizabissoli@gmail.com

Universidade Federal do Espírito Santo, Centro de Ciencias Humanas e Naturais, Av. Fernando Ferrari, Goiabeiras, CEP 29075910 - Vitória, ES, Brasil, Telefone: (27) 40092506. 
